\title{
Snow Avalanches in Forested Terrain: Influence of Forest Parameters, Topography, and Avalanche Characteristics on Runout Distance
}

Author(s): Michaela Teich, Perry Bartelt, Adrienne Grêt-Regamey andPeter Bebi

Source: Arctic, Antarctic, and Alpine Research, 44(4):509-519.

Published By: Institute of Arctic and Alpine Research (INSTAAR), University of Colorado

DOI: http://dx.doi.org/10.1657/1938-4246-44.4.509

URL: http://www.bioone.org/doi/full/10.1657/1938-4246-44.4.509

BioOne (www.bioone.org) is a nonprofit, online aggregation of core research in the biological, ecological, and environmental sciences. BioOne provides a sustainable online platform for over 170 journals and books published by nonprofit societies, associations, museums, institutions, and presses.

Your use of this PDF, the BioOne Web site, and all posted and associated content indicates your acceptance of BioOne's Terms of Use, available at www.bioone.org/page/terms_of_use.

Usage of BioOne content is strictly limited to personal, educational, and non-commercial use. Commercial inquiries or rights and permissions requests should be directed to the individual publisher as copyright holder. 


\section{Snow Avalanches in Forested Terrain: Influence of Forest Parameters, Topography, and Avalanche Characteristics on Runout Distance}

\author{
Michaela Teich* ${ }^{*} \neq$ \\ Perry Bartelt* \\ Adrienne Grêt-Regamey† and \\ Peter Bebi* \\ *WSL Institute for Snow and Avalanche \\ Research SLF, Flüelastrasse 11, 7260 Davos \\ Dorf, Switzerland \\ $†$ Planning of Landscape and Urban Systems \\ PLUS, Swiss Federal Institute of Technology \\ ETH, Wolfgang-Pauli-Strasse 15, 8093 \\ Zurich, Switzerland \\ \$Corresponding author: teich@slf.ch
}

\begin{abstract}
Mountain forests are recognized as an effective biological protection measure against snow avalanches. To investigate how forests decelerate snow avalanches, we analyzed two data sets from the European Alps. The first data set contained 43 small to medium avalanches which released in forests and either stopped in forested terrain within 50 to $400 \mathrm{~m}$ or ran through forests and stopped in unforested terrain with a maximum runout distance of 700 $\mathrm{m}$. The second data set consisted of 44 medium to large avalanches ( 360 to $1800 \mathrm{~m}$ in runout distance) which all stopped within forests, but started above treeline. Statistical dependencies between predictor variables on forest conditions, terrain features and avalanche characteristics (60 in total), and the response variable avalanche runout distance were investigated. Clear differences between avalanches that released in forests and avalanches that released above forests were observed. Forest structural parameters, in particular the starting zone stem density of trees with small diameters $(1-15 \mathrm{~cm})$, had a significant effect on runout distances of small to medium avalanches, which released in evergreen coniferous and mixed forests $\left(r_{S}=-0.3 ; p=0.015\right)$. Beyond a threshold of $200 \mathrm{~m}$ this effect was negligible for runout distances of avalanches which were still in motion. In contrast, forest structure did not affect runout distances of medium to large avalanches, which started above treeline, but forests in general were still able to slow avalanche speeds and limit avalanche runout. Furthermore, runout distance was significantly affected by avalanche size characteristics for medium to large avalanches, while avalanche size was less important in determining the runout distance of small avalanches, which released in forest openings. These results emphasize that it is important to treat these two cases differently in protection forest as well as natural hazard management.
\end{abstract}

\section{Introduction}

Mountain forests play an important role in avalanche protection (Brang et al., 2006). Especially in populated areas in which the risk of avalanches limits habitability (Grêt-Regamey and Straub, 2006), there is considerable interest in understanding how forest structure affects the frequency and magnitude of avalanches (Gruber and Bartelt, 2007; Bebi et al., 2009). In addition, avalanches in forested terrain are a threat to recreationists, who often access forests while out-of-bounds (off-piste) skiing. Avalanches released in forests are usually small; however, depending on ecological, meteorological, and topographical conditions, they may develop into larger avalanches which can pose hazard to settlements and infrastructure below the forest (SLF, 2000).

Forest structure in terms of crown closure, tree density, and size and distribution of forest gaps in combination with topography directly influences the probability of avalanche releases in forests and, therefore, is the determining factor that controls the protective capacity of mountain forests (e.g. Bebi et al., 2001; Schneebeli and Bebi, 2004; Viglietti et al., 2010). While the protective effect of forests on avalanche formation in potential starting zones is relatively well understood (for a review see Bebi et al., 2009), much less is known about the secondary protective effect of forests on avalanche runout. Previous studies have shown that this effect is limited to decelerating small to medium avalanches (Salm, 1978; Gubler and Rychetnik, 1991; Schneebeli and Bebi, 2004), while speed reduction of avalanches by forests seems to be negligible for large destructive avalanches (de Quervain, 1979; Margreth, 2004). According to field observations and estimates based on physical arguments, snow avalanche events released more than approximately $150 \mathrm{~m}$ above treeline are sufficiently strong to break or uproot trees (Schneebeli and Bebi, 2004; Bebi et al., 2009). Since tree fracture consumes relatively little of the avalanche energy, large avalanches released high above the treeline are able to destroy forests without significant deceleration (Bartelt and Stöckli, 2001). However, the decelerating effect of different forest structures on small avalanches released in forests or directly above the treeline has not yet been quantified (Bebi et al., 2009). In addition, recent observations from the European Alps emphasize the importance of studying also potential decelerating effects of forests on larger avalanches (LfU, 2010). It has been shown that medium to large avalanches released high above treeline destroyed large areas of mountain forests, but, surprisingly, stopped in forests before reaching the valley bottom (LfU, 2010). These observations again emphasize the intimate relationship between avalanche size and the protective capacity of forests.

Due to their sporadic occurrence and a non-continuous monitoring, observation data on avalanches in forested areas are rare. Avalanches in forested terrain are often not recognized or docu- 
mented as they are not of primary importance compared to large destructive avalanches in open terrain endangering settlements, infrastructure, and human lives. However, they do play an important role in protection forest management. Decisions on silvicultural interventions need to consider the effect of different forest structures in potential starting zones, the avalanche track, and runout zones so that forests can fulfill the protective function effectively (Teich and Bebi, 2009). Furthermore, when it comes to decisions about the size and extent of avalanche defense structures in potential starting zones within forested areas or directly above the treeline, forest and civil engineers need to know if forests with a certain structure or extent are capable of hindering avalanches that would endanger settlements and infrastructure.

In particular, we hypothesize that mountain forests growing in the avalanche path are capable of significantly influencing avalanche runout distances by deceleration, due to increasing friction and decreasing mass. This hypothesis is based on avalanche experiments at the Swiss Vallée de la Sionne site, which show that avalanche size controls flow regimes and, therefore, avalanche stopping behavior (Bartelt et al., 2012). While for small to medium avalanches this effect strongly depends on forest structure, we expect that forest structure is negligible for large destructive avalanches.

In this paper, we present an analysis of the influence of forest parameters, terrain features, and avalanche characteristics on avalanche runout distances in forested terrain. Among 60 collected variables we identify the most important ones, which affect avalanche runout distances of small to medium avalanches, which started in forests, as well as for medium to large avalanches released above the treeline. Compared to the present study, previous analyses of forest-avalanche interactions with focus on the avalanche path did not contain such a large set of variables, especially on forest parameters (e.g. McClung, 2003; Takeuchi et al., 2011). Furthermore, based on the analysis of a small subset on wet snow avalanches, we draw and discuss general assumptions of differences between wet and dry snow avalanches in forested terrain.

\section{Methods}

\section{AVALANCHE DATA SETS}

We analyzed two existing data sets from Europe containing 87 avalanches of different size. For avalanche size definitions we refer to typical path lengths where "small" $<100 \mathrm{~m}$ avalanche length, "medium" < $1000 \mathrm{~m}$, and "large" < $2000 \mathrm{~m}$ (McClung and Schaerer, 2006; EAWS, 2012). The first data set consists of 43 small to medium wet and dry snow avalanches from the Swiss Alps ranging between 50 and $700 \mathrm{~m}$ in runout distance, which were observed during the winters 1986-1990. All these avalanches started in forests and detailed data on avalanche characteristics and forest parameters in the avalanche starting zone were collected in the field close to the events (Tables 1 and 2; for more details see Schneebeli and Meyer-Grass, 1993). We refer to this data set as 'forest avalanches' since we define a forest avalanche in general as an avalanche that released in forests. The avalanche starting points of forest avalanches were specified as $x, y$-coordinates and runout distances were recorded from the starting point in $5 \mathrm{~m}$ steps as the horizontal projection. To reconstruct and project the actual avalanche runout distances, we determined a representative ava- lanche flow line following the stream network identified by a GIS software.

The second data set on 44 dry snow avalanches is from Germany, mostly observed during one big avalanche cycle in February 2009 in the Bavarian Alps. In contrast to the Swiss data set, these avalanches are larger with runout distances from 360 to $1800 \mathrm{~m}$ measured in horizontal projection along a GIS-identified stream network. They started mainly above the treeline, but stopped in forests. Therefore, we refer to this data set as 'avalanches released into forest.'

Probability densities show that avalanche runout distance is not normally distributed, at least for forest avalanches (Fig. 1). Runout distance of avalanches released into forest may be approximated as a normal distribution. The forest avalanches data set contains 57 continuous and categorical variables describing forest parameters, terrain features, and avalanche characteristics compared to avalanches released into forest with 36 variables (Tables 1 and 2). The availability of detailed forest data was reduced for avalanches released into forest to a few parameters, which were obtained from orthophotographs.

\section{DESCRIPTION OF SELECTED TERRAIN VARIABLES}

Selected variables on terrain features were determined for both data sets from digital elevation models (DEMs) as described below. The analyses were mainly based on high-resolution DEMs, which are gained from airborne lidar (light detection and ranging) data with a spatial resolution of $2 \mathrm{~m}$ and a vertical accuracy of approximately $0.5 \mathrm{~m}$. This was done separately for the avalanche starting zone, the avalanche track, and the runout zone. Each zone is defined as one-third in length of the total runout area. In contrast to the forest avalanches data set, runout areas of avalanches released into forest were mapped close to the event from helicopter flights or site visits. To estimate the potential runout areas of forest avalanches, we applied the two-dimensional numerical avalanche dynamics program RAMMS (Christen et al., 2010) and back-calculated all avalanches. The simulation results were verified with photographs taken shortly after most events.

\section{Selected Terrain Variables:}

Mean slope angle: Average slope angles in the starting zone, the avalanche track, and the runout zone as well as an overall mean slope angle were determined from DEMs by GIS zonal statistics.

Cross-slope curvature: Plan curvature was calculated using the ArcGIS (ESRI, 2011) tool "Curvature,", which determines the relative position of a cell to its surrounding pixels in a $3 \times 3$ pixel moving-window. Positive values indicate a concave or gullied slope $(+1)$, negative values denote a convex slope or ridge $(-1)$, and values around 0 mean almost no curvature, respectively, flat terrain $(0)$. The mean value of the curvature raster was taken for each zone to assign the corresponding category.

Downslope curvature: The profile curvature was calculated similar to the cross-slope curvature. Positive values indicate a downwards decrease in slope angle (concave, +1 ), negative values describe a downwardly increasing slope angle (convex, -1 ), and values around 0 characterize an almost plain slope (0). 
TABLE 1

Descriptive statistics for continuous variables for the data sets on 'forest avalanches' $(n=43)$ and 'avalanches released into forest' $(n=$ 44); NA = no data.

\begin{tabular}{|c|c|c|c|c|c|c|}
\hline \multirow[b]{2}{*}{ Variable } & \multicolumn{3}{|c|}{ Forest avalanches } & \multicolumn{3}{|c|}{ A. released into forest } \\
\hline & Mean & STD & Range & Mean & STD & Range \\
\hline \multicolumn{7}{|l|}{ Avalanche characteristics } \\
\hline Runout distance (m) & 235 & 173 & $50-700$ & 1085 & 370 & $360-1800$ \\
\hline Fracture height $(\mathrm{cm})$ & 55 & 40 & $5-140$ & 130 & 23 & $50-200$ \\
\hline Release width (m) & 15 & 12 & $1-50$ & 180 & 153 & $20-800$ \\
\hline Snow height at release $(\mathrm{cm})$ & 86 & 46 & $15-180$ & NA & NA & NA \\
\hline Estimated height of new snow at release $(\mathrm{cm})$ & 9 & 17 & $0-60$ & NA & NA & NA \\
\hline Width of runout zone $(\mathrm{m})$ & NA & NA & NA & 76 & 59 & $15-300$ \\
\hline \multicolumn{7}{|l|}{ Terrain Features } \\
\hline Mean slope angle ${ }^{a}$ in the starting zone $\left(^{\circ}\right)$ & 39 & 5 & $30-50$ & 39 & 4 & $28-46$ \\
\hline Mean slope angle in the avalanche track $\left({ }^{\circ}\right)$ & 35 & 5 & $24-43$ & 36 & 5 & $26-47$ \\
\hline Mean slope angle in the runout zone $\left(^{\circ}\right)$ & 33 & 5 & $19-39$ & 26 & 6 & $15-38$ \\
\hline Mean slope angle (overall) $\left(^{\circ}\right.$ ) & 36 & 4 & $29-43$ & 34 & 3 & $27-41$ \\
\hline Starting point elevation (m a.s.l.) & 1584 & 543 & $800-2215$ & 1523 & 149 & $940-1840$ \\
\hline Runout zone elevation (m a.s.l.) & 1421 & 526 & $695-2140$ & 907 & 133 & $600-1240$ \\
\hline Vertical drop (m) & 163 & 109 & $35-415$ & 616 & 180 & $220-1100$ \\
\hline \multicolumn{7}{|l|}{ Forest $t^{b}$ parameters } \\
\hline Length of forest gap at release $\mathrm{c}^{\mathrm{c}}(\mathrm{m})$ & 28 & 22 & $0-90$ & NA & NA & NA \\
\hline Distance to first trees ${ }^{\mathrm{d}}(\mathrm{m})$ & NA & NA & NA & 274 & 234 & $0-955$ \\
\hline Distance to forest $(\mathrm{m})$ & NA & NA & NA & 515 & 360 & $0-1200$ \\
\hline Distance through forest $(\mathrm{m})$ & 146 & 93 & $30-400$ & 521 & 271 & $100-1300$ \\
\hline Number of stems per hectare $\mathrm{DBH}^{\mathrm{e}} 1-15 \mathrm{~cm}(\mathrm{No} / \mathrm{ha})$ & 371 & 584 & $0-3251$ & NA & NA & NA \\
\hline Number of stems per hectare $\mathrm{DBH}>6 \mathrm{~cm}(\mathrm{No} / \mathrm{ha})$ & 450 & 370 & $0-2083$ & NA & NA & NA \\
\hline Number of stems per hectare $\mathrm{DBH}>16 \mathrm{~cm}(\mathrm{No} / \mathrm{ha})$ & 230 & 161 & $0-840$ & NA & NA & NA \\
\hline Mean diameter at breast height $\mathrm{DBH}>1 \mathrm{~cm}(\mathrm{~cm})$ & 22 & 12 & $2-61$ & NA & NA & NA \\
\hline Mean diameter at breast height DBH $>16 \mathrm{~cm}(\mathrm{~cm})$ & 34 & 11 & $0-61$ & NA & NA & NA \\
\hline Dominant height $^{\mathrm{f}}(\mathrm{m})$ & 19 & 6 & $0-28$ & NA & NA & NA \\
\hline First branches above ground $(\mathrm{m})$ & 3.6 & 2.3 & $0-10$ & NA & NA & NA \\
\hline Total canopy density ${ }^{\mathrm{g}}(\%)$ & 40 & 22 & $0-82$ & NA & NA & NA \\
\hline Norway spruce (Picea abies (L.) H.KARST.) canopy density (\%) & 27 & 34 & $0-100$ & NA & NA & NA \\
\hline European larch (Larix decidua MıL.) canopy density (\%) & 33 & 38 & $0-100$ & NA & NA & NA \\
\hline Swiss stone pine (Pinus cembra L.) canopy density (\%) & 7 & 14 & $0-55$ & NA & NA & NA \\
\hline Other conifers canopy density $(\%)$ & 1 & 6 & $0-30$ & NA & NA & NA \\
\hline European beech (Fagus sylvatica L.) canopy density (\%) & 23 & 35 & $0-90$ & NA & NA & NA \\
\hline Other broadleaf trees canopy density $(\%)$ & 5 & 8 & $0-23$ & NA & NA & NA \\
\hline Basal $\operatorname{area}^{\mathrm{h}}$ DBH $1-15 \mathrm{~cm}\left(\mathrm{~m}^{2} / \mathrm{ha}\right)$ & 1 & 2 & $0-9$ & NA & NA & NA \\
\hline Basal area DBH $>16 \mathrm{~cm}\left(\mathrm{~m}^{2} / \mathrm{ha}\right)$ & 24 & 16 & $0-83$ & NA & NA & NA \\
\hline Basal area on total area (\%) & 45 & 27 & $0-90$ & NA & NA & NA \\
\hline Norway spruce (Picea abies (L.) H.KARsT.) basal area (\%) & 22 & 34 & $0-100$ & NA & NA & NA \\
\hline European larch (Larix decidua MiLL.) basal area (\%) & 35 & 40 & $0-100$ & NA & NA & NA \\
\hline Swiss stone pine (Pinus cembra L.) basal area (\%) & 9 & 19 & $0-85$ & NA & NA & NA \\
\hline Other conifers basal area $(\%)$ & 2 & 11 & $0-56$ & NA & NA & NA \\
\hline European beech (Fagus sylvatica L.) basal area (\%) & 26 & 40 & $0-100$ & NA & NA & NA \\
\hline Other broadleaf trees basal area $(\%)$ & 3 & 6 & $0-23$ & NA & NA & NA \\
\hline Regeneration (height $1-130 \mathrm{~cm}$ ) (No/ha) & 718 & 1505 & $0-7200$ & NA & NA & NA \\
\hline
\end{tabular}

a See text for further description of variable.

${ }^{\mathrm{b}}$ Forests are characterized by a maximum distance between trees of $25 \mathrm{~m}$, a minimum canopy density of $20 \%$, and a dominant height above $3 \mathrm{~m}$. ${ }^{\mathrm{c} D o w n s l o p e}$ measured maximum extent of a forest opening.

${ }^{\mathrm{d}}$ Distance from the starting point to single trees or group of trees which are not defined as forests.

e Outside bark diameter at breast height measured $1.37 \mathrm{~m}$ above the forest floor on the uphill side of the tree.

${ }^{\mathrm{f}}$ Mean height of the 100 biggest trees per ha.

gercentage of the ground covered by a vertical projection of the tree crown.

${ }^{\mathrm{h}}$ Cross-section area of a tree stem in $\mathrm{m}^{2}$ measured at breast height. 
TABLE 2

Categorical predictor variables and description of categories.

\begin{tabular}{|c|c|}
\hline Variable & Description and categories \\
\hline \multicolumn{2}{|l|}{ Avalanche characteristics } \\
\hline Avalanche type & $\begin{array}{l}\text { Form of the avalanche release: Avalanche started from (1) loose snow which slipped } \\
\text { out from the snow surface and forms a triangle shaped release area; (2) a cohesive } \\
\text { snow slab or; (3) gliding snow often triggered by an increasing water amount in the } \\
\text { snow cover }\end{array}$ \\
\hline Wet or dry snow avalanche & Liquid water in the release (wet) or not (dry) \\
\hline Position of sliding surface ${ }^{a}$ & $\begin{array}{l}\text { Within snow cover (1); New snow fracture (2); Old snow fracture (3); On the ground } \\
\text { (4) }\end{array}$ \\
\hline \multicolumn{2}{|l|}{ Terrain Features } \\
\hline Aspect & $\begin{array}{l}\text { Divided compass aspect ( } 8 \text { sectors): } 1=\mathrm{N} ; 2=\mathrm{NE} ; 3=\mathrm{E} ; 4=\mathrm{SE} ; 5=\mathrm{S} ; 6= \\
\quad \mathrm{SW} ; 7=\mathrm{W} ; 8=\mathrm{NW}\end{array}$ \\
\hline $\begin{array}{l}\text { Cross-slope curvature in starting zone, } \\
\text { avalanche track and runout zone }{ }^{\mathrm{b}}\end{array}$ & $\begin{array}{l}\text { Concave or gullied slope }(+1) \text {; Convex slope or ridge }(-1) \text {; Almost no curvature or } \\
\text { open slope }(0)\end{array}$ \\
\hline $\begin{array}{l}\text { Downslope curvature in starting zone, } \\
\text { avalanche track and runout zone } \mathrm{e}^{\mathrm{b}}\end{array}$ & Concave $(+1)$; Convex $(-1)$; Flat $(0)$ \\
\hline $\begin{array}{l}\text { Surface roughness in starting zone, } \\
\text { avalanche track and runout zone }\end{array}$ & Low (1); Medium (2); High (3) \\
\hline \multicolumn{2}{|l|}{ Forest parameters } \\
\hline Stop or no-stop in forest & $\begin{array}{l}\text { Avalanche stopped within forest (1); Avalanche ran through forest and stopped in unfor- } \\
\text { ested areas (0) }\end{array}$ \\
\hline Release in forest & Avalanche started within forest (1); Avalanche started above forest (0) \\
\hline Forest type & $\begin{array}{l}\text { (1) "Mixed forests" contain deciduous forest, mostly dominated by European beech } \\
\text { (Fagus silvatica L.) and mixed alpine forests; (2) Norway spruce (Picea abies (L.) } \\
\text { H.KARST.) dominated "Evergreen coniferous forest'; (3) "Deciduous coniferous for- } \\
\text { est', formed by European larch (Larix decidua MiLL.) at the upper tree line }\end{array}$ \\
\hline Crown closure & $\begin{array}{l}\text { (1) Dense forest (Crown coverage }>90 \% \text { ); (2) Loose (Crown coverage 70-90\%); (3) } \\
\text { Scattered (Crown coverage 40-70\%); (4) Scattered to open (Crown coverage 20-40 } \\
\% \text { ) and; (5) Open (Crown coverage }<20 \% \text { ); Based on the classification system of Bebi } \\
\text { et al. (2001), crown closure was delineated and digitized in GIS by orthophotographs } \\
\text { analyses. }\end{array}$ \\
\hline Vertical structure & (1) Non; (2) One layer; (3) Two layers; (4) > Two layer; (5) Clumped or grouped \\
\hline Stage of development & $\begin{array}{l}\text { (1) Non; (2) Seedlings; (3) Pole stage forest }(8<\mathrm{DBH}<30 \mathrm{~cm}) \text {; (4) Young timber } \\
\text { trees }(31<\mathrm{DBH}<40 \mathrm{~cm}) ;(5) \text { Middle-aged timber trees }(41<\mathrm{DBH}<50 \mathrm{~cm}) \text {; } \\
\text { (6) Old timber trees }(\mathrm{DBH}>51 \mathrm{~cm})\end{array}$ \\
\hline
\end{tabular}

${ }^{\text {a}}$ Variable is not available for avalanches released into forest.

${ }^{\mathrm{b}} \mathrm{See}$ text for further description of these variables.

Surface roughness: Local surface roughness is expressed as the standard deviation of the terrain height undulations (differences in elevation) within a $3 \times 3$ pixel moving-window and averaged within the starting zone, the avalanche track, and the runout zone. Before that, we calculated a continuously inclining trend raster for each zone of the avalanche area and subtracted it from the DEM to obtain a flattened raster containing local height differences only. Categories are low (1), medium (2), and high (3) surface roughness. Thresholds for the categories were defined by comparing the results of the DEM analysis with sporadic field samples.

\section{STATISTICAL ANALYSIS}

Since many of the studied variables are categorical rather than continuous and the dependent response variable avalanche runout distance is not normally distributed (Fig. 1), we calculated Spearman's rank correlation coefficient $\left(r_{S}\right)$ to determine statistical dependencies between independent predictor variables describing forest parameters, terrain features and avalanche characteristics, and avalanche runout distance. In contrast to other correlation coefficients, $r_{S}$ is known as non-parametric and does not assume a linear relationship between response and predictor variables. A significant Spearman correlation can result when response and predictor variables are related by any monotonic function (Kendall, 1990). We defined a correlation statistically significant if the respective $p$-value is $0.01<p \leq 0.05$ and highly significant for $p \leq 0.01$. We tested all available variables against the avalanche runout distance separately for the forest avalanches and the avalanches released into forest data sets and for two subsets on wet and dry snow forest avalanches within the data set forest avalanches.

Furthermore, we calculated regression trees to test the relative importance of the variables that most influence changes in avalanche runout distance, i.e. to identify parameters which classify our data set significantly and to find thresholds for this classification. Regression trees analyze nonlinear relationships in a robust way and split the data iteratively into increasingly more homogenous partitions by constructing a set of decision rules on the predictor variables by an exhaustive search procedure (Breiman et al., 


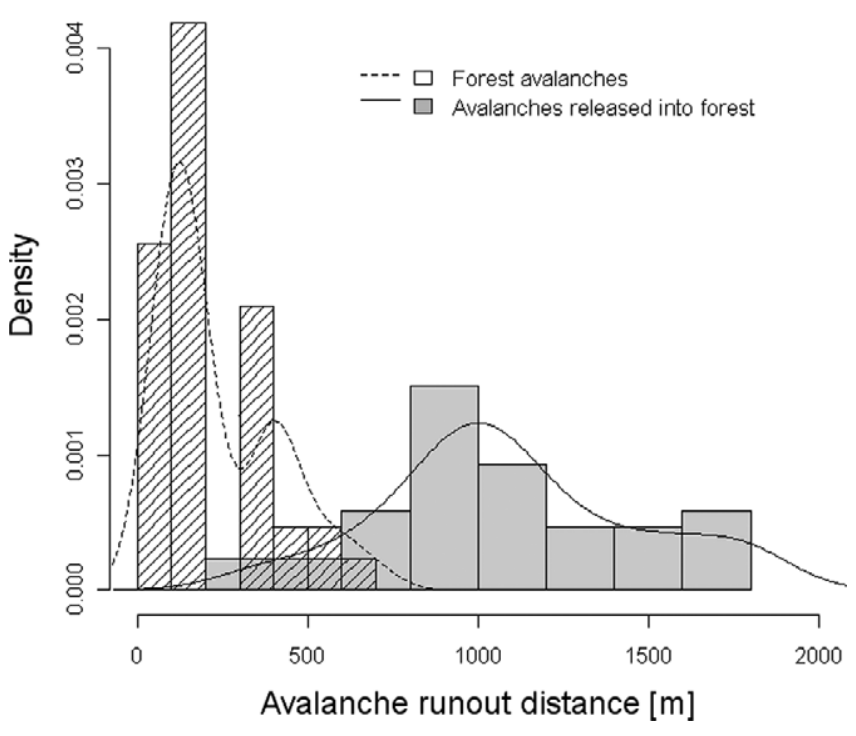

FIGURE 1. Probability densities and probability distributions of avalanche runout distances for the data sets 'forest avalanches' and 'avalanches released into forest.'

1984). The selected split is the one that maximizes the homogeneity of the two resulting groups with respect to the response variable (Prasad et al., 2006). The regression tree model of the "party" add-on package to the " $\mathrm{R}$ " system for statistical computing was used to model conditional inference trees (Hothorn et al., 2006; R Development Core Team, 2011). This non-parametric class of regression trees is applicable to all kinds of regression problems by embedding tree-structured regression models into a well defined theory of conditional inference. To avoid overfitting, predefinitions were set as a significance level of $95 \%$ (respectively $p \leq 0.05$ ), which must be exceeded in order to implement a split, and a minimum of $20 \%$ of the number of observations should result in a terminal node.

\section{Results}

\section{FOREST AVALANCHES}

Several forest variables show significant or highly significant correlations with avalanche runout distance of forest avalanches (Table 3). Avalanches that stopped in forests had significantly smaller runout distances compared to avalanches that ran through forests and stopped in unforested terrain (Fig. 2), which supports our initial hypothesis. The regression tree model (vertical drop excluded) identified 'stop or no-stop in forest' as the most important variable among the predictor variables influencing avalanche runout (Fig. 3), i.e. avalanches stopped in forests within a mean runout distance of approximately $150 \mathrm{~m}$. The distance through forest was of secondary importance, with a threshold of $100 \mathrm{~m}$. Therefore, the general existence of forests in the avalanche path seems to play an important role on the first 100-200 $\mathrm{m}$ for the decelerating effect of forests.

Correlations between parameters characterizing forest structure and runout distance were found for the type of forest, the number of stems per hectare, and the mean diameter at breast height (DBH). Avalanches traveling through deciduous coniferous forests
TABLE 3

Highly significant** $(p \leq 0.01)$ and significant* $(0.01<p \leq 0.05)$ Spearman rank correlation coefficients $\left(r_{S}\right)$ for avalanche runout distance of 'forest avalanches.'

\begin{tabular}{lrl}
\hline \hline \multicolumn{1}{c}{ Predictor variable } & $r_{S}$ & $p$-value \\
\hline Avalanche characteristics & & \\
Avalanche type & -0.39 & $0.011^{*}$ \\
Terrain Features & & \\
Cross-slope curvature in the avalanche track & -0.33 & $0.030^{*}$ \\
Cross-slope curvature in the runout zone & -0.36 & $0.019^{*}$ \\
Surface roughness in the starting zone & 0.37 & $0.013^{*}$ \\
$\quad$ Vertical drop & 0.97 & $<.0001^{* *}$ \\
Forest parameters & & \\
Stop or no-stop in forest & -0.67 & $<.0001^{* *}$ \\
Distance through forest & 0.35 & $0.021^{*}$ \\
Forest type & 0.33 & $0.033^{*}$ \\
Number of stems per hectare DBH $1-15 \mathrm{~cm}$ & -0.30 & $0.015^{*}$ \\
Mean diameter at breast height DBH $>1 \mathrm{~cm}$ & 0.36 & $0.017^{*}$ \\
\hline
\end{tabular}

formed by European larch (Larix decidua MiLL.) have significantly longer runout distances compared to evergreen coniferous and mixed forests, in that order. Forest density characterized by the number of stems per hectare has a significant impact on avalanche runout for the class of trees with a DBH ranging between 1 and $15 \mathrm{~cm}$. Mean diameter at breast height shows a positive correlation, i.e. avalanches released in forests containing stems of larger mean DBHs have longer runout distances. Compared to large trees where these relationships are not that strong, small trees seems to be especially important in the starting zone and on the first $200 \mathrm{~m}$ of the avalanche path for limiting avalanche runout.

Terrain had a strong influence on runout distance in terms of cross-slope curvature in the avalanche track and the runout zone

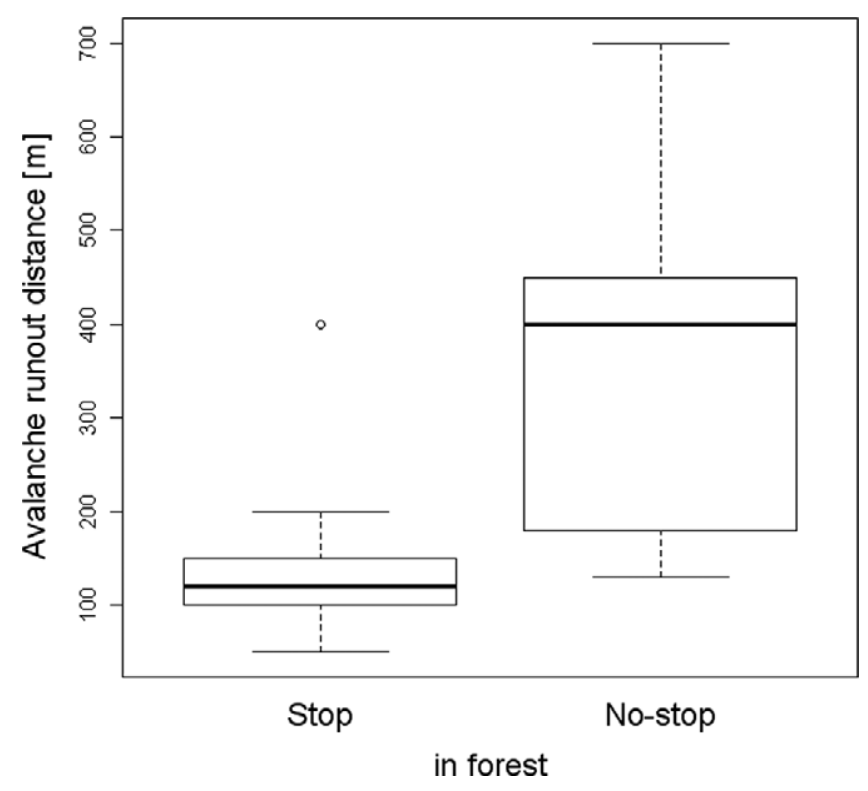

FIGURE 2. Differences in avalanche runout distance for avalanches which stopped or did not stop in forest for the data set on 'forest avalanches.' Boxplots show minimum, the lower quartile (Q $0.25)$, the median $(Q 0.5)$, the upper quartile $Q 0.75)$, and maximum values for each category. Point is relative position of extreme value. 


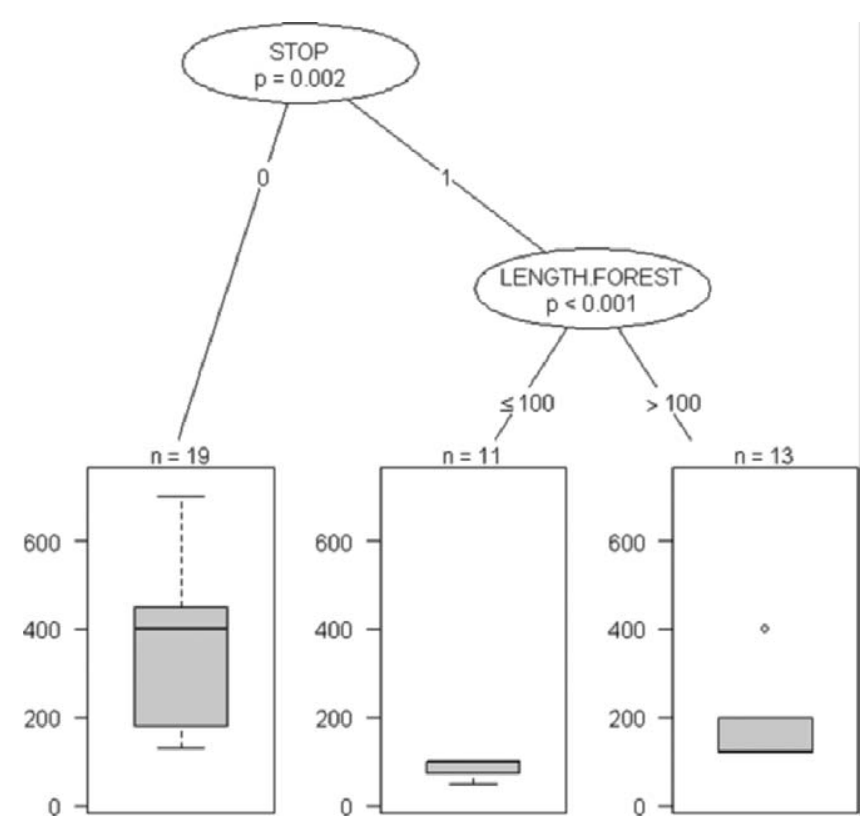

FIGURE 3. Regression tree model of avalanche runout distances based on predictor variables with significant or highly significant correlations excluding vertical drop for the data set on 'forest avalanches' $(n=43)$. The response variable avalanche runout distance [m] is displayed in the boxplots at the bottom of the tree showing minimum, the lower quartile $(Q 0.25)$, the median $(Q \quad 0.5)$, the upper quartile $(Q \mathbf{Q} 0.75)$, and maximum values. The $n$-value exhibits the number of avalanches which are explained by the corresponding variable. STOP = Stop [1] or no-stop [2] in forest, LENGTH.FOREST $=$ Distance through forest $[\mathrm{m}]$.

(Fig. 4). Small to medium avalanches, which started in forests, were significantly longer in concave gullied terrain compared to flat terrain or convex slopes, emphasizing that more channelized terrain generally delivers larger avalanches to the runout zone. Surface roughness in the starting zone shows a positive correlation with runout distance, i.e. higher local height differences lead to larger avalanches. Steepness in the starting zone, the avalanche track, and the runout zone as well as the overall mean slope angle did not correlate with runout distances of forest avalanches.

There is no general relationship between parameters characterizing avalanche size, like fracture height and release width, and runout distance. The only variable on avalanche characteristics that appeared as statistically significant was the avalanche type, where glide avalanches have smaller runout distances than loose snow and slab avalanches, in that order.

\section{SUBSETS ON WET AND DRY SNOW FOREST AVALANCHES}

In addition to the statistical analyses of the whole data set on forest avalanches, we calculated Spearman rank correlations for the two subsets on wet $(n=28)$ and dry snow avalanches $(n=16)$ and retained only variables with significant and highly significant correlations as summarized in Table 4 . The runout distances of the subsets on wet and dry snow avalanches range between 50-700 $\mathrm{m}$ and $60-600 \mathrm{~m}$, respectively, but on average dry snow forest avalanches tend to have longer runout distances $($ mean $=306 \mathrm{~m})$ than wet snow forest avalanches $($ mean $=193 \mathrm{~m})$.

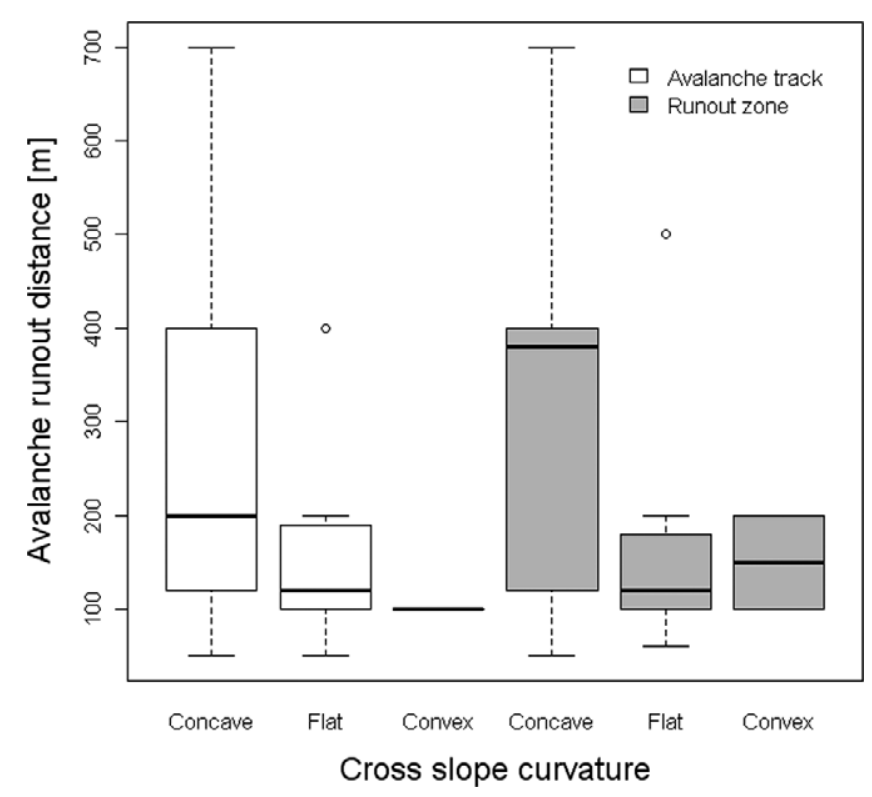

FIGURE 4. Differences in avalanche runout distance for concave, flat, and convex cross-slope curvature in the avalanche track and the runout zone of the data set on 'forest avalanches.' Boxplots show minimum values, the lower quartile ( $Q$ 0.25), the median ( $Q$ 0.5), the upper quartile (Q 0.75), and maximum values for each category of cross slope curvature. Points are relative positions of extreme values.

For wet snow avalanches, the distance an avalanche runs through the forest correlates strongly with avalanche runout distance in a negative direction, indicating that a long traveling distance through forests leads to short runout distances. When analyzing wet and dry snow forest avalanches separately, the height of first branches above ground and the European beech (Fagus silvatica $\mathrm{L}$.) basal area percentage appeared as new variables correlating significantly with avalanche runout distance. The variable first branches above ground characterize the mean crown length of the respective forest. A small distance to first branches means that tree crowns almost reach the forest floor and vice versa. For wet snow forest avalanches this relationship is positive in contrast to dry snow forest avalanches with a negative correlation coefficient, i.e. long tree crowns are linked to shorter runout distances of wet snow avalanches. In contrast, shorter runout distances of dry snow avalanches are correlated with shorter tree crowns which could indicate a higher forest density. The percentage of beech on basal area influences runout distances of wet snow forest avalanches in the way that a higher percentage causes shorter runout distances.

In contrast to the results for the whole data set on forest avalanches where terrain steepness had no influence on avalanche runout distance, overall terrain steepness shows positive correlations with runout distance for dry snow forest avalanches (mean $=32^{\circ}$ ), while a decrease in slope angle $\left(\right.$ mean $\left.=38^{\circ}\right)$ is correlated with increasing runout distances of wet snow forest avalanches. Cross-slope curvature affects dry snow forest avalanches the most, i.e. more channelized terrain leads to longer runout distances compared to flat or convex terrain. Avalanche size characteristics had no influence on runout distances of both wet and dry snow avalanches. 
TABLE 4

Highly significant ${ }^{* *}(p \leq 0.01)$ and significant* $(0.01<p \leq 0.05)$ Spearman rank correlation coefficients $\left(r_{S}\right)$ for avalanche runout distance of the subsets on wet and dry snow avalanches within the data set on 'forest avalanches.'

\begin{tabular}{|c|c|c|c|c|}
\hline \multirow[b]{2}{*}{ Predictor variable } & \multicolumn{2}{|l|}{ Dry } & \multicolumn{2}{|l|}{ Wet } \\
\hline & $r_{S}$ & $p$-value & $r_{S}$ & $p$-value \\
\hline \multicolumn{5}{|l|}{ Avalanche characteristics } \\
\hline Avalanche type & - & - & -0.47 & $0.014 *$ \\
\hline \multicolumn{5}{|l|}{ Terrain Features } \\
\hline Mean slope angle in the starting zone & - & - & -0.45 & $0.019 *$ \\
\hline Mean slope angle in the avalanche track & - & - & -0.41 & $0.032 *$ \\
\hline Mean slope angle in the runout zone & - & - & -0.51 & $0.007 * *$ \\
\hline Mean slope angle (overall) & 0.55 & $0.027 *$ & -0.60 & $0.001 * *$ \\
\hline Cross-slope curvature in the avalanche track & -0.58 & $0.018^{*}$ & - & - \\
\hline Cross-slope curvature in the runout zone & -0.73 & $0.001 * *$ & - & - \\
\hline Surface roughness in the starting zone & - & - & 0.54 & $0.003 * *$ \\
\hline Runout zone elevation & -0.647 & $0.007 * *$ & & \\
\hline Vertical drop & 0.96 & $<.0001^{* *}$ & 0.98 & $<.0001 * *$ \\
\hline \multicolumn{5}{|l|}{ Forest parameters } \\
\hline Stop or no-stop in forest & -0.83 & $<.0001^{* *}$ & -0.51 & $0.006 * *$ \\
\hline Distance through forest & - & - & 0.84 & $<.0001 * *$ \\
\hline First branches above ground & -0.56 & $0.024 *$ & 0.46 & $0.016^{*}$ \\
\hline European beech basal area percentage & - & - & -0.41 & $0.035^{*}$ \\
\hline
\end{tabular}

\section{AVALANCHES RELEASED INTO FOREST}

Spearman rank correlations for the data set on avalanches released into forest show different statistical dependencies between predictor variables and avalanche runout distance compared to forest avalanches (Tables 3 and 5); forest structural parameters did not correlate with avalanche runout distance of avalanches released into forest.

Highly significant positive correlations were calculated for the distance to forest, the distance to first trees, and the distance an avalanche ran through forest. Avalanches which started high above treeline had longer runout distances than avalanches with short distances to first trees or forest. An increase in distance through forest is correlated with increasing runout distances. The distance to forest is correlated with the distance through forest $\left(r_{S}=-0.32\right)$, highlighting that avalanche parameters characterizing avalanche

\section{TABLE 5}

Highly significant** $(p \leq 0.01)$ and significant* $(0.01<p \leq 0.05)$ Spearman rank correlation coefficients $\left(r_{S}\right)$ for avalanche runout distance of the data set on 'avalanches released into forest.'

\begin{tabular}{lrl}
\hline \hline Predictor variable & $r_{S}$ & $p$-value \\
\hline $\begin{array}{l}\text { Avalanche characteristics } \\
\quad \text { Release width }\end{array}$ & 0.38 & $0.028^{*}$ \\
$\quad$ Terrain Features & & \\
$\quad$ Surface roughness in the avalanche track & 0.64 & $0.0002^{* *}$ \\
$\quad$ Starting point elevation & 0.39 & $0.002^{* *}$ \\
$\quad$ Runout zone elevation & -0.49 & $0.0003^{* *}$ \\
$\quad$ Vertical drop & 0.79 & $<.0001^{* *}$ \\
Forest parameters & & \\
$\quad$ Distance through forest & 0.41 & $0.005^{* *}$ \\
$\quad$ Distance to first trees & 0.77 & $<.0001^{* *}$ \\
Distance to forest & 0.57 & $<.0001^{* *}$ \\
\hline & & \\
\end{tabular}

size are much more important for this set of avalanches compared to forest avalanches.

Regression tree models emphasize these findings: Parameters characterizing avalanche size split the data set significantly into four groups of varying mean runout distances (Fig. 5). Vertical drop is the most important variable as well as of secondary importance especially for larger avalanches of this data set. In addition, release width splits the smaller avalanches at a threshold of $130 \mathrm{~m}$ into two groups of different mean runout distances. If vertical drop is excluded from the regression tree model, the distance to forest is the most important variable followed by the distance through forest of secondary importance and again distance to forest of third importance (Fig. 6). For example, an avalanche stops at a mean runout distance of $1000 \mathrm{~m}$ if the distance to forest ranges between 500 and $725 \mathrm{~m}$ and the distance through forest does not exceed a threshold of $500 \mathrm{~m}$.

\section{Discussion}

The present study contains statistical analyses of 60 variables on forest parameters, terrain features, and avalanche characteristics, and their effects on the avalanche runout distances of small to medium avalanches released in forests as well as on medium to large avalanches released above the treeline. In particular, the large number of predictor variables characterizing forest structure is much more comprehensive than in previous studies on the influence of forests in the avalanche path on avalanche magnitude, frequency, or runout distance (e.g. Frey et al., 1987; Butler and Malanson, 1992; McClung, 2003; Takeuchi et al., 2011).

\section{AVALANCHES STARTING IN FORESTS}

Our results highlight the importance of forests within the first $100-200 \mathrm{~m}$ of the avalanche path, since avalanches which stopped 


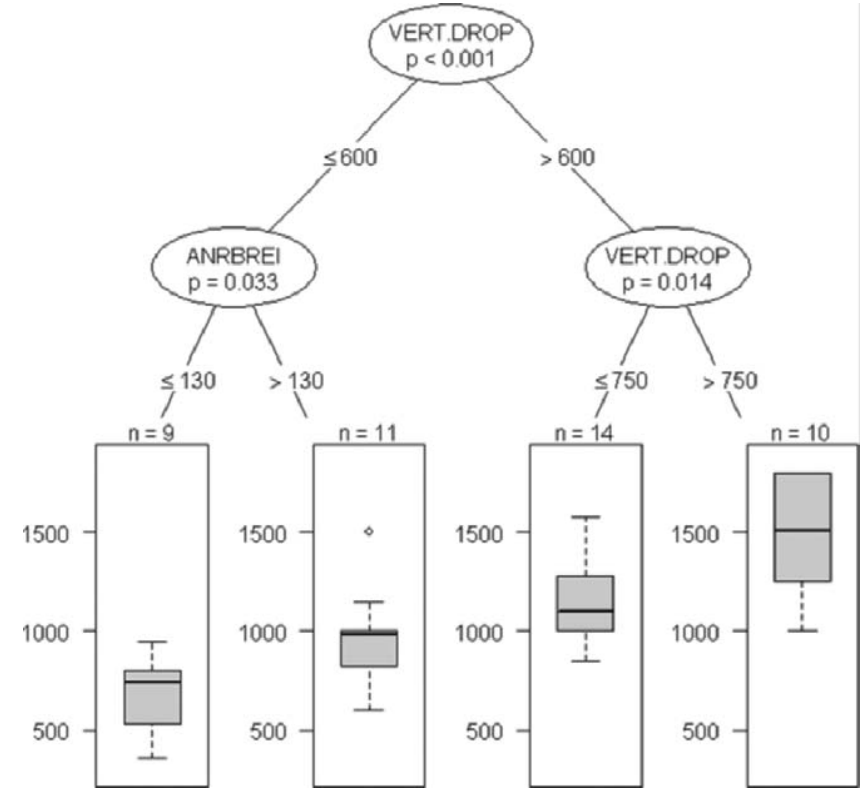

FIGURE 5. Regression tree model of avalanche runout distances based on predictor variables with significant or highly significant correlations for the data set on 'avalanches released into forest' $(n=44)$. The response variable avalanche runout distance $[\mathrm{m}]$ is displayed in the boxplots at the bottom of the tree showing minimum, the lower quartile ( $Q$ 0.25), the median ( $Q$ 0.5), the upper quartile ( $Q$ 0.75), and maximum values. The $n$-value exhibits the number of avalanches which are explained by the corresponding variable. VERT.DROP $=$ Vertical drop $[\mathrm{m}]$, ANRBREI $=$ Release width [m].

in forests were significantly smaller in runout distance compared to avalanches which ran through forests and stopped in unforested terrain. Cross-correlations emphasize the general effect of forest growing in avalanche starting zones since 'stop or no-stop in forest' is neither related to avalanche size characteristics nor to the distance through forest or other forest parameters. Forests of a certain structure are capable of stopping small avalanches within a critical distance of 200-400 m. Field surveys undertaken in British Columbia forests already pointed to a relationship between length of slope and susceptibility of the downslope forests to avalanche damage; slope lengths greater than $200 \mathrm{~m}$ are considered to pose moderate risk, while slope lengths greater than $400 \mathrm{~m}$ are considered to pose high risk, in combination with other factors (Weir, 2002). The significant decelerating effect of older forests on smaller avalanches by overturning trees and entraining the heavy root cluster was already highlighted by Bartelt and Stöckli (2001). However, we could also verify the positive effect of forests containing smaller stem diameters $(1<\mathrm{DBH}<15 \mathrm{~cm})$; such forests are generally more dense compared to forests dominated by stems of larger diameters $(\mathrm{DBH}>16 \mathrm{~cm})$, where the number of stems in the starting zone did not influence runout distance significantly. We assume that, due to crowns starting higher above ground, there is less biomass in the zone where avalanches accelerate, so that they might turn into far-reaching avalanches; a high density of small diameter stems limits the avalanche mass. In addition, smaller bending stresses and the complete deflection of such trees consume avalanche energy resulting in a significant deceleration of small avalanches (Johnson, 1987). Thresholds for mean diameters of

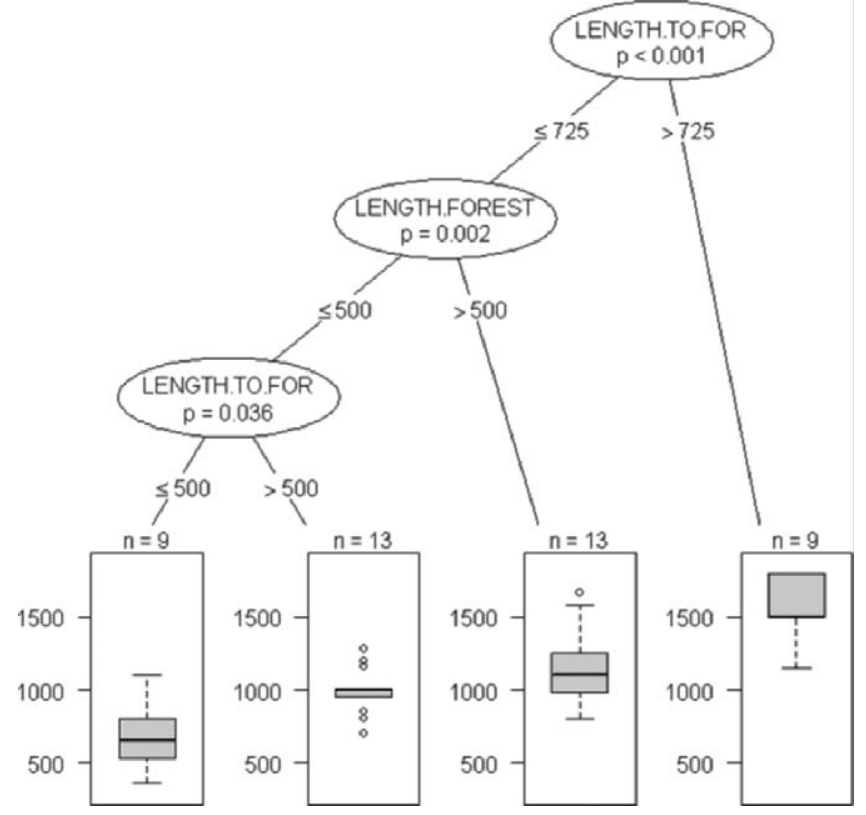

FIGURE 6. Regression tree model of avalanche runout distances based on predictor variables with significant or highly significant correlations excluding vertical drop for the data set on 'avalanches released into forest' $(n=44)$. The response variable avalanche runout distance $[\mathrm{m}]$ is displayed in the boxplots at the bottom of the tree showing minimum, the lower quartile $(Q 0.25)$, the median (Q 0.5), the upper quartile (Q 0.75), and maximum values. The $n$ value exhibits the number of avalanches which are explained by the corresponding variable. LENGTH.TO.FOREST = Distance to forest [m], LENGTH.FOREST = Distance through forest [m].

breakage of different coniferous specious in several avalanche paths in the Swiss Alps were determined as approximately 10-20 $\mathrm{cm}$, which lies within our class of small-diameter stems (Tiri, 2009). Small trees which are not broken or uprooted during an avalanche event can still fulfill their protective function afterwards.

The influence of the forest type on runout distance reveals the characteristics of these mountain forest ecosystems. Avalanches that traveled through deciduous coniferous forests were significantly longer than avalanches that ran through evergreen coniferous and mixed forests. Larch stands near timberline have an open, less dense structure supported by cross-correlation results where the forest type does correlate significantly with the number of stems per hectare for all DBH classes $\left(-0.71<r_{S}<-0.50\right)$. A positive correlation was found between forest type and mean $\mathrm{DBH}$ of trees larger than $1 \mathrm{~cm}$ in diameter $\left(r_{S}=0.41\right)$. In contrast to deciduous coniferous forests, the growth of small avalanches is prevented in evergreen coniferous and mixed forests, also containing a high number of small diameter stems, because of an increased crown biomass, higher interception effects, and, therefore, less snow entrainment in the avalanche path.

Terrain had a significant influence on avalanche runout distance in terms of cross-slope curvature in the avalanche track and runout zone, surface roughness in the starting zone, and the vertical drop. A higher vertical drop is related to path scale and may imply higher snow erosion in the avalanche path followed by greater destructive effects and longer runout distances (McClung, 2003; McClung and Schaerer, 2006). However, due to a limited range of 
slope angles of our data set, such high correlations between runout distances and vertical drop could be expected. Surface roughness in the starting zone shows positive correlations with runout distance that indicates that a larger snow supply is needed for potential avalanche releases in areas with high surface roughness.

In the present study, surface roughness was a predictor variable in terms of local terrain height differences without regard to ground vegetation or dead wood. However, concerning effective protection forest management, especially after storm events, the possible influence of dead wood on avalanche magnitude needs to be discussed briefly. Fallen logs, remnant stumps and root plates of upturned trees can prevent the formation of small avalanches (Schneebeli and Bebi, 2004). If an avalanche is already moving, tree entrainment in the debris enlarges the avalanche in mass and volume (Bartelt and Stöckli, 2001). Therefore, it could be highly valuable to keep tree debris in place, if a storm damages a protection forest (Bartelt and Stöckli, 2001). At least over the first 10 to 20 years after a storm event, dead wood still increases surface roughness in the starting zone and can prevent small avalanche releases (Putallaz, 2010).

Correlations of cross-slope curvature in the avalanche track and the runout zone with runout distance could be related to snow entrainment with more mass added in channelized terrain delivering larger avalanches to the runout zone compared to flat terrain or convex slopes (McClung, 2003; McClung and Schaerer, 2006). This corresponds to the longer runout distances found for avalanches released in deciduous coniferous forests. The starting point elevations in this type of forest are higher compared to those in evergreen coniferous and mixed forest and, therefore, avalanches starting in larch forests are more prone to gullied terrain. In our study, slope angle had no significant influence on runout distances of forest avalanches. However, avalanches start in forests generally on steeper slopes compared to avalanches in open terrain (Schneebeli and Bebi, 2004). Another study has also shown that no terrain variable including slope angle accounted for over $20 \%$ of variations in runout distance of avalanches in forested terrain (Butler, 1979). They concluded that this depends strongly on the region where avalanches were observed.

The influence of the avalanche type (glide snow avalanches are shorter compared to slab or loose snow avalanches, in that order) could possibly be explained by the amount of wet snow avalanches in our data set. This avalanche type starts from a slow gliding surface often triggered by an increasing water amount in the snowpack (Clarke and McClung, 1999) and, since wet snow in motion has a much higher friction on the sliding surface compared to dry snow, leads to shorter runout distances (McClung and Schaerer, 2006).

\section{WET AND DRY SNOW AVALANCHES IN FORESTED TERRAIN}

Separate analyses of the two subsets on wet and dry snow avalanches show similar correlations as the whole data set, but also reveal specific characteristics of the two categories. In general, the type of snow condition (wet or dry snow) and the type of forest correlates significantly $\left(r_{S}=-0.53\right)$, i.e. wet snow avalanches do occur more often at lower elevations in mixed forests in contrast to dry snow avalanches which release more frequently in evergreen and deciduous coniferous forests at high elevations. Beech is a typical tree species of low altitude areas. A higher beech basal area percentage was negatively correlated with avalanche runout distance of wet snow forest avalanches. This could be related to a general increase in forest density, which reduces the speed of small wet snow avalanches in deciduous and mixed forests. Observations of wet snow avalanches in forested terrain are rare, but the few examples verify our findings, e.g. the speed of three wet snow avalanches in very steep terrain $\left(45^{\circ}\right.$ mean slope angle) was reduced by dense beech forests without damaging any trees and even small regeneration was not affected by the events (Imbeck and MeyerGrass, 1988).

Crown length expressed in height of first branches above ground appeared as correlating significantly with runout distances for both subsets, for dry snow forest avalanches in a negative direction and for wet snow forest avalanches in a positive direction, i.e. the lower the crown the longer the runout distances of dry snow avalanches and the opposite for wet snow avalanches. Branch lopping is often linked to tree fracture and low energy consumption which increases avalanche mass and, therefore, flow energy (Bartelt and Stöckli, 2001). Dry snow avalanches occur more frequently in less dense coniferous forests near timberline, with triangle-shaped crowns starting close to the ground, and are more prone to avalanche destructive forces. Wet snow avalanches release more often in deciduous forests with crowns starting higher above the ground. Trees are less vulnerable and have a positive decelerating effect on wet snow avalanche runout as discussed before.

In contrast to forest avalanches, where slope angle had no significant influence on runout distance, terrain steepness shows positive correlations for dry snow forest avalanches, while a decrease in slope angle is correlated with increasing runout distances of wet snow forest avalanches. In general, terrain steepness restricts the amount of snow because of given shear strength, which leads to higher fracture depths, higher snow erosion in the avalanche path, and longer runout distances, and wet snow in motion has much higher friction at the sliding surface, which distinguishes it from dry snow (McClung and Schaerer, 2006). These relationships could explain both cases. First, increasing slope angles of the subset on dry snow avalanches and less friction at the sliding surface lead to generally longer runout distances compared to wet snow avalanches. And second, decreasing slope angles along the avalanche path lead to increased snow erosions and increasing runout distances of wet snow avalanches. Furthermore, conditions on ground vegetation in the avalanche path as well as an increasing amount of liquid water at the sliding surface can preclude significant energy dissipation along the lateral margins of the flow (Butler and Malanson, 1992). Resulting continued high energy levels can favor a more excessive travel of wet snow avalanche in the runout zone with decreasing slope angles in contrast to dry snow avalanches (Butler and Malanson, 1992). However, similar observations were made before where an inclining runout zone showed a positive correlation with mean avalanche size without a clear physical explanation (McClung, 2003).

Keeping in mind that the number of observations within the two subsets was limited, we draw first assumptions on the behavior of wet snow avalanches in forested terrain, since studies on this topic are especially rare. Few documented events on larger wet snow avalanches, which occurred in forests, have shown their 
destructive potential (SLF, 1952). Future research should focus on wet snow avalanches in forested terrain; as with increasing winter temperatures under future climate conditions (Laternser and Schneebeli, 2003), the occurrence of destructive wet snow avalanches in forests might increase and raises the risk to settlements and infrastructure (Martin et al., 2001).

\section{AVALANCHES RELEASED ABOVE TREELINE}

Compared to forest avalanches, forest structure does not play such an important role for avalanche runout distances of avalanches released into forest. Forests in general affect runout distance in terms of distance to forest (including distance to first trees) and distance through forest. While the distance to forest limits avalanche runout distance, the distance an avalanche travelled through forest seems to increase avalanche mass through entrainment of stems in the avalanche debris (Bartelt and Stöckli, 2001). A threshold for the distance to forest appeared within the second regression tree model (vertical drop excluded). Thus, forests in general may be able to limit runout distances of larger avalanches even if the avalanches are released high above treeline, i.e. with a maximum distance to forest of approximately $700 \mathrm{~m}$. Takeuchi et al. (2011) came to similar conclusions by studying a large-scale dry slab avalanche that stopped shortly after penetrating a cedar forest. Forests in combination with topography are able to decelerate large avalanches (Anderson and McClung, 2012).

Release width as a parameter characterizing avalanche size shows significant positive correlations with runout distance, which distinguishes avalanches released into forest from forest avalanches. Surface roughness in the avalanche track shows highly significantly positive correlations with runout distance indicating that higher local terrain undulations determine larger snow supplies and snow entrainment leading to longer runout distances.

The differences between the two data sets on forest avalanches and avalanches released into forest emphasize that it is important to treat these two cases differently in protection forest as well as natural hazard management. Especially for small to medium avalanches released in forests or directly above the treeline, the protective power of forests depends sensitively on the density of the forest stand by preventing avalanche releases (Schneebeli and MeyerGrass, 1993; Bebi et al., 2001) as well as by decelerating and stopping already moving avalanches as seen in the present study. However, our data set on 87 observed avalanches in total is still limited. To strengthen our findings on the effect of forest structure in the avalanche path on runout distance, future studies should focus on collecting more reliable data on avalanches in forested terrain. This topic is especially important, since recurrence periods of avalanches that damage forests and might endanger settlements and infrastructure are short; between 20 and 30 years as observed in Switzerland (Föhn, 1979).

\section{Conclusions}

According to our hypotheses, we could demonstrate that forest structure has a significant influence on runout distances of small to medium avalanches released in forest openings. Especially on the first 100-200 $\mathrm{m}$ from the starting point, evergreen coniferous and mixed forests also containing small-diameter stems $(1-15 \mathrm{~cm})$ limited avalanche mass such that runout distances did not exceed $200-400 \mathrm{~m}$. Beyond this threshold, this effect is negligible for runout distances of avalanches that are still in motion.

For larger avalanches released high above treeline, the effect of different forest structures along the avalanche path is negligible, but forests in general are still able to slow avalanche speeds and limit runout distances. In contrast to avalanches released in forests, avalanche size in terms of release width and fracture height controls runout distances significantly as these avalanches behave similar to avalanches in open unforested terrain.

Therefore, an effective protection forest management helps to form forest stands that decelerate and stop small to medium avalanches released in forests. Furthermore, forest and civil engineers should take this effect of forests and its limitations into account when establishing the dimensions of avalanche defense structures in potential starting zones within forested areas or directly above treeline.

Our findings reveal necessary research needs on forest-avalanche interactions along the avalanche path in order to define thresholds of avalanche size where forests have a decelerating effect on avalanches. Future research should include a better quantification of thresholds between small and large avalanches according to existing size classification systems for avalanches in unforested areas, since an improved knowledge and understanding of interactions between avalanches and forests in the avalanche path is necessary to support optimized and regionally adapted decision making in protection forest as well as natural hazard management.

\section{Acknowledgments}

We thank Thomas Feistl, Armin Fischer, and Christian Ginzler for their assistance collecting the data as well as the Bavarian avalanche warning service for providing the data set on avalanches released into forest. We also thank Natalie Zurbriggen and two anonymous reviewers for valuable comments on earlier versions of the manuscript. This study was funded by the CCES (Competence Center Environment and Sustainability of the ETH Domain) within the project MOUNTLAND.

\section{References Cited}

Anderson, G., and McClung, D., 2012: Snow avalanche penetration into mature forest from timber-harvested terrain. Canadian Geotechnical Journal, 49(4): 477-484.

Bartelt, P., and Stöckli, V., 2001: The influence of tree and branch fracture, overturning and debris entrainment on snow avalanche flow. Annals of Glaciology, 32: 209-216.

Bartelt, P., Bühler, Y., Buser, O., Christen, M., and Meier, L., 2012: Modeling mass-dependent flow regime transitions to predict the stopping and depositional behavior of snow avalanches. Journal of Geophysical Research-Earth Surface, 117: F01015, http://dx.doi .org/10.1029/2010JF001957.

Bebi, P., Kienast, F., and Schönenberger, W., 2001: Assessing structures in mountain forests as a basis for investigating the forests dynamics and protective function. Forest Ecology and Management, 145: 3-14.

Bebi, P., Kulakowski, D., and Rixen, C., 2009: Snow avalanche disturbances in forest ecosystems-State of research and implications for management. Forest Ecology and Management, 257(9): 1883-1892. Brang, P., Schönenberger, W., Frehner, M., Schwitter, R., Thormann J.-J., and Wasser, B., 2006: Management of protection forests in the 
European Alps: an overview. Forest Snow and Landscape Research, 80: 23-44.

Breiman, L., Friedman, J., Olshen, R. A., and Stone, J. C., 1984: Classification and Regression Trees. Belmont, California, U.S.A.: Wadsworth, $358 \mathrm{pp}$.

Butler, D. R., 1979: Snow avalanche path terrain and vegetation, Glacier National Park, Montana. Arctic and Alpine Research, 11: 17-32.

Butler, D. R., and Malanson, G. P., 1992: Effects of terrain on excessive travel distance by snow avalanches. Northwest Science, 66(2): 77-85.

Christen, M., Kowalski, J., and Bartelt, P., 2010: RAMMS: numerical simulation of dense snow avalanches in three-dimensional terrain Cold Regions Science and Technology, 63: 1-14.

Clarke, J., and McClung, D., 1999: Full-depth avalanche occurrences caused by snow gliding, Coquihalla, British Columbia, Canada. Journal of Glaciology, 45(151): 539-546.

de Quervain, M., 1979: Wald und Lawinen. Proceedings of the IUFRO Seminar Mountain Forests and Avalanches, Davos, Switzerland 219-231.

EAWS, 2012: European avalanche size classification, http://www.avalanches.org.

ESRI, 2011: ArcGIS desktop: release 10. Redlands, California: Environmental Systems Research Institute.

Föhn, P. M. B., 1979: Avalanche frequency and risk estimation in forest sites. Mitteilungen des Eidgenössischen Institutes für Schnee und Lawinenforschung, 37: 241-254.

Frey, W., Frutiger, H., and Good, W., 1987: Openings in the forest caused by forest deperishment and their influence on avalanche danger. In Fujimori, T., and Kimura, M. (eds.), Human Impacts and Management of Mountain Forests. Ibaraki, Japan: Forestry and Forest Products Research Institute, 223-238.

Grêt-Regamey, A., and Straub, D., 2006: Spatially explicit avalanche risk assessment linking Bayesian networks to a GIS. Natural Hazards and Earth System Sciences, 6(6): 911-926.

Gruber, U., and Bartelt, P., 2007: Snow avalanche hazard modelling of large areas using shallow water numerical methods and GIS. Environmental Modelling \& Software, 22(10): 1472-1481.

Gubler, H., and Rychetnik, J., 1991: Effects of forest near the timberline on avalanche formation. Snow, Hydrology and Forests in High Al pine Areas, Proceedings of the Vienna Symposium, August 1991. IAHS Publication, 205: 19-37.

Hothorn, T., Hornik, K., and Zeileis, A., 2006: Unbiased recursive partitioning: a conditional inference framework. Journal of Computational and Graphical Statistics, 15(3): 651-674.

Imbeck, H., and Meyer-Grass, M., 1988: Waldlawinen am Gugelberg. Schweizerische Zeitschrift für Forstwesen, 139(2): 145-152.

Johnson, E. A., 1987: The relative importance of snow avalanche disturbance and thinning on canopy plant populations. Ecology, 68 43-53.

Kendall, M. G., 1990: Rank Correlation Methods. 5th edition. London: Arnold, 260 pp.

Laternser, M., and Schneebeli, M., 2003: Long-term snow climate trends of the Swiss Alps (1931-1999). International Journal of Climatology, 23: 733-750.

LfU, 2010: Der Lawinenwinter 2008/09-Dokumentation von Unfallund Schadenslawinen. UmweltSpezial, Bayerisches Landesamt für Umwelt ( $L f U$ ), unpublished.
Margreth, S., 2004: Die Wirkung des Waldes bei Lawinen. Forum für Wissen 2004: 21-26.

Martin, E., Giraud, G., Lejeune, Y., and Boudart, G., 2001: Impact of a climate change on avalanche hazard. Annals of Glaciology, 32: 163-167.

McClung, D., and Schaerer, P., 2006: The Avalanche Handbook. 3rd edition. Seattle: The Mountaineers Books, 293 pp.

McClung, D. M., 2003: Magnitude and frequency of avalanches in relation to terrain and forest cover. Arctic, Antarctic, and Alpine Research, 35(1): 82-90.

Prasad, A. M., Iverson, L. R., and Liaw, A., 2006: Newer classification and regression tree techniques: bagging and random forests for ecological prediction. Ecosystems, 9(2): 181-199.

Puttalaz, J.-M., 2010: Protection à long terme contre les avalanches sur les surface de chablis. Etude sur l'efficacité mécanique des arbres au sol. M.Sc. thesis. Department of Environmental Sciences, ETH Zurich, Switzerland, 116 pp.

R Development Core Team, 2011: R: a Language and Environment for Statistical Computing. Vienna, Austria: R Foundation for Statistical Computing. http://www.R-project.org.

Salm, B., 1978: Snow forces on forest plants. Proceedings of the IUFRO Seminar Mountain Forests and Avalanches, Davos, Switzerland: $157-182$.

Schneebeli, M., and Bebi, P., 2004: Snow and avalanche control. In Burley, J., Evans, J., and Youngquist, J. A. (eds.), Encyclopedia of Forest Sciences. Oxford: Elsevier, 397-402.

Schneebeli, M., and Meyer-Grass, M., 1993: Avalanche starting zones below the timberline-structure of forest. Proceedings of the International Snow Science Workshop, Breckenridge, CO, 4-8 October 1992: 176-181.

SLF, 1952: Schnee und Lawinen in den Schweizeralpen Winter 1950/ 51. Weissfluhjoch/Davos: Winterberichte des Eidgenössischen Institutes für Schnee- und Lawinenforschung, 15: $231 \mathrm{pp}$.

SLF, 2000: Der Lawinenwinter 1999: Ereignisanalyse. Davos: Eidgenössischen Institutes für Schnee- und Lawinenforschung, Hrgs., 588 pp.

Takeuchi, Y., Torita, H., Nishimura, K., Hirashima, H., 2011: Study of a large-scale dry slab avalanche and the extent of damage to a cedar forest in the Makunosawa valley, Myoko, Japan. Annals of Glaciology, 52(58): 119-128.

Teich, M., and Bebi, P., 2009: Evaluating the benefit of avalanche protection forest with GIS-based risk analyses-A case study in Switzerland. Forest Ecology and Management, 257(9): 1910-1919.

Tiri, R., 2009: Interaktionen zwischen verschiedenen Baumeigenschaften und Lawinen. M.Sc. thesis. Department of Environmental Sciences, ETH Zurich, Switzerland, 80 pp.

Viglietti, D., Letey, S., Motta, R., Maggioni, M., and Freppaz, M., 2010: Snow avalanche release in forest ecosystems: a case study in the Aosta Valley Region (NW-Italy). Cold Regions Science and Technology, 64(2): 167-173.

Weir, P., 2002: Snow Avalanche Management in Forested Terrain Victoria, British Columbia: Research Branch, British Columbia Ministry of Forests, Land Management Handbook, 55: 190 pp., www.for.gov.bc.ca/hfd/pubs/Docs/Lmh/Lmh55.htm.

MS accepted July 2012 